\title{
AXIAL CRUSH BEHAVIOUR OF SQUARE COLUMN WITH EXTERNAL TAPERED PLUNGER
}

\author{
Amir R. A. Ghani ${ }^{*}, 1$ and M. A. Hassan ${ }^{2}$ \\ ${ }^{I}$ Faculty of Mechanical Engineering, Universiti Teknologi MARA, 40450 Shah Alam, Selangor, MALAYSIA \\ ${ }^{2}$ Mechanical Engineering Department, Assiut University, Faculty of Engineering Assiut, Egypt
}

Received 25 June 2013, accepted 25 July 2013

\begin{abstract}
Thin-walled square columns are generally used as impact energy absorber in automotive structures due to their ease of fabrication and installation, high energy absorption capacity in terms of progressive plastic deformation and long stroke. However, the main drawback of standard square column is the high initial peak force. An external tapered plunger is proposed to overcome this shortcoming while at the same time, improving the impact performance. Static and dynamic axial crushing were performed by theoretical and finite element analysis to determine the initial peak force (IPF), crush force efficiency (CFE) and plastic specific energy absorption (SEA) of columns with external plunger of various taper angles. The simulations results were validated by experiments. It was found that the external plunger significantly enhanced the column impact performance and the deformation characteristics as well. Comparison with plain square column was carried out and it was found that the concentric plunger reduced the initial peak force and increased the crush force efficiency for both static and dynamic loading conditions.
\end{abstract}

Keyword: Crush behavior, Energy absorption, Progressive failure, Square column, Finite element analysis.

\section{Introduction}

Crashworthiness is the measure of performance of vehicles during collisions. The aims of structural crashworthiness are to minimise the impact load and deceleration of the vehicles and occupants and to dissipate the kinetic energy resulting from the impact event [1]. Energy absorbers in the form of columns and frustas of various shapes and sizes are mainly used for impact protection of vehicles during collision. Ductile materials such as steels and aluminium are the preferred choice as they exhibit large plastic deformation before total fracture. These materials absorb the excessive kinetic energy during impact by various mechanisms such as friction, fracture, shearing, bending, tension, crushing and plastic deformation.

Widely used geometries such as square and circular tubes, frustas and polygons subjected to axial and lateral loadings have been extensively studied for the past five decades $[2,3]$. The need to further optimise the structures has prompted researchers to experiment with new geometries, configurations and material combinations. Zhang and Chang [4] carried out comparative studies of energy absorption characteristics of foam filled and multi cell column. Both foam filled and multi cell columns exhibited higher energy absorption as compared to plain columns. In the foam filled column, foam filler acted as a semi-elastic foundation for the sidewall which resulted in decreasing buckling length of sidewall and thus higher plastic deformations and buckling load. In the multi-cell column, the additional bending and stretching of inner cell faces plus the main four faces

Corresponding author.

E-mail address: amirdzi@gmail.com 
contribute to the increase of energy absorption. However, the additional stiffness resulted in a high initial peak force which can cause destructive effect on the occupants. The incorporation of a trigger mechanism by means of a groove managed to reduce the high initial peak force while maintaining the energy absorption performance.

G.H. Daneshi and S.J. Hosseinipou [5] carried out experimental work on grooved thin walled tubes subjected to axial compression. The function of the groove in the tube is to force the plastic deformation to occur at predetermined intervals along the tube. The aims were to improve the uniformity of the load-displacement behaviour and better predict the energy absorption capacity of the tubes. Quassi-static axial crushing tests were performed with different groove distance. The results showed favourable characteristics where the grooved tubes exhibited lower initial peak forces and more uniform and stable crushing modes and mean forces.

Xiong Zhang et al. [6] carried out numerical investigation on a new tube configuration called retractable/telescopic tube; straight retractable (SR) and tapered retractable (TR), subjected to axial crushing. The inversion process of the proposed tubes under axial crushing was simulated by using the non-linear finite element code LS-Dyna. A comparative study based on the impact performance indices of the proposed tubes with the plain circular tube was conducted. The results showed that the proposed tubes outperformed the plain circular tube in almost every aspects of performance indices (lower peak force and higher crush force efficiency (CFE) and specific total efficiency (STE)), except the specific energy absorption (SEA). In addition, a parametric study was carried out to investigate the effects of the geometric parameters on the behaviour of the retractable tubes. It was discovered that the behaviour of SR tubes is greatly influenced by the width of the annular connection zone, while the behaviour of the TR tubes is found to be insensitive. A three-level retractable tube was also tested and it was found to have an even better performance.

Zhang, X.W. et al. [7] studied the effect of a buckling initiator on the response of an axially crushed square tube. The buckling initiator consisted of a pre-hit column with pulling strips attached to both sides of the inner tube near the impacted end. When subjected to axial impact, the pre-hit column will be hit by the striker first which will cause the strips to pull the two opposite walls of the square tube, creating some geometric imperfections. The results showed a considerable decrease in initial peak force while little effect was observed on the mean force and deformation mode. The reduction of peak force was found to be greatly influenced by the pre-hit height. To minimize the length and maximize the effective stroke of the tube, the pulling strips must be positioned as close as possible to the top edge of the tube. Added advantages of this system are stiffness of the intact square tube in its normal structural function is maintained and a more stable and uniform crushing mode is ensured. A simplified analytical model to relate the reduction of initial peak load with the geometric imperfection was developed. The model was able to predict the effectiveness of the buckling initiator to a certain extent.

Zhang, X.W. et al. [8] extended the use of this buckling initiator in circular aluminium tubes subjected to dynamic axial loading. Experimentally, the effect of different number of pulling strips, pre-hit height and inclined angle of the pulling strips on the initial peak force and mean crushing force were studied. Results showed that for large progressive deformation, the buckling initiator changed the failure mode from ring or mixed mode to diamond mode. The most stable deformation tended to be diamond mode with three pulling strips. With a suitable selection of pre-hit height, the initial peak force was reduced

Journal of Engineering Sciences, Assiut University, Faculty of Engineering, Vol. 41, No. 4, July, 2013, E-mail address: jes@aun.edu.eg 
Amir R. A. Ghani, M. A. Hassan, Axial Crush Behaviour of Square Column with External Tapered Plunger, pp. $1498-1517$

by $30 \%$. A simplified theoretical analysis to explain the reduction of the initial peak force and the energy dissipation mechanisms was developed and showed good agreements with experimental results.

Yamashita, M. et al. [9] studied the dynamic axial crushing of aluminium tubular structure with hat-shaped configuration. The hat-shaped cross sections were constructed by bonding and riveting a flanged $\mathrm{C}$ channel with a flat plate. A buckling initiator which consisted of two solid blocks attached to the side wall at specified height of the structure was used to initiate the first plastic buckling lobe. The solid blocks provided inertia force which caused bending of the walls. The crush strength of the bonded hat-shaped cross section was found to be higher than the riveted one because of the smaller gap formation at the bonded hat flange portion.

Current researches explore the use of trigger mechanism incorporated in structures that aims to induce failure in a desired manner and producing impact response which are optimized for a wide range of conditions. This study will focus on the crush behavior and progressive deformation of square column with an external plunger as the trigger mechanism. Crush performance indices are used to evaluate the efficiency of the proposed mechanism. The square column was chosen due to its ease of fabrication, versatility and superior impact energy absorption, especially by progressive buckling deformation, and widely used in automotive structures to withstand the frontal collision. Crush performance of plain Square column and columns with a proposed taper plunger are studied by numerical and analytical models under dynamic and static loading as well. Experiments are used to validate the FE-model and the results are discussed and concluded.

\section{Crush performance indices}

Crush performance of a structure can be expressed in term of its specific energy absorption (SEA), Es which is the ratio of energy absorbed to the unit mass of the material. It allows direct comparison of similarly shaped structures made from different materials.

$$
E_{s}=\frac{W}{V \rho}
$$

where $\mathrm{W}=$ total energy absorbed

$\mathrm{V}=$ volume of material

$\rho=$ density of material

Crush force efficiency (CFE), $\eta c$ is the useful measure for the uniformity of collapse force. It is defined as the ratio of mean load, Fmean to initial peak force, Fpeak. An ideal absorber will have a crush force efficiency of $100 \%$ which is very difficult to achieve in reality. CFE of most tubular structures subjected to axial loading are between 30 to $50 \%$.

$$
\eta_{C}=\frac{F_{\text {mean }}}{F_{\text {peak }}}
$$

The initial peak force (IPF) is also of equal importance as this force tends to be very high and may cause severe injury to the occupant. Therefore, in some structures, trigger mechanism is added to the existing system as a mean to reduce the high initial peak force.

Journal of Engineering Sciences, Assiut University, Faculty of Engineering, Vol. 41, No. 4, July, 2013,E-mail address: jes@aun.edu.eg 


\section{Proposed trigger mechanism}

In the present study, an external tapered plunger is added to plain square column as the trigger mechanism to improve the crush performance. The design configurations and dimensions are given in Figure 1 and Table 1. Plunger taper angle, $\theta$, plunger height, $\mathrm{H}$, column width, $\mathrm{D}$, column height, $\mathrm{L}$, and thickness, $\mathrm{t} 1$, are of the most important parameters that will be studied and optimized numerically and analytically. The results will be verified experimental under impact test.

\section{Finite element model}

The plain square column was modeled in Abaqus as a 3D deformable shell. The bottom plate which represents the support and the top plate which represents the compression platen/impactor were modeled as rigid bodies. Approximately 8000 4-noded linear quadrilateral explicit shell element of type S4R were used for the column. The S4R elements are of reduced integration type with enhanced hourglass control. For the top and bottom plates, 8 4-noded rigid linear quadrilateral elements of type R3D4 were used. The external plunger, was modeled as rigid surface and consisted of 1500 R3D4 elements. Figure 2 shows the finite element model of the square column with external plunger.

The column is made of aluminium 6063-T5. General material properties of the column are given in Table 2 whereas the true stress-strain curve obtained from uniaxial tensile test is shown in Figure 3. The material mechanical behavior can be safely described by elasticplastic linear strain hardening model.

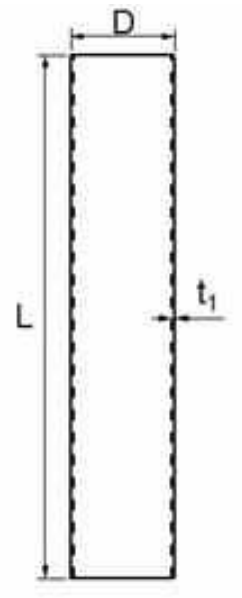

Plain column

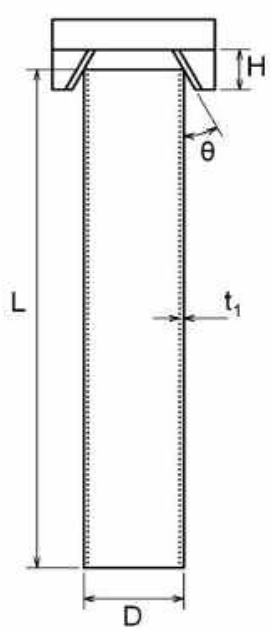

Column with external plunger

Fig. 1. Design configurations

Journal of Engineering Sciences, Assiut University, Faculty of Engineering, Vol. 41, No. 4, July, 2013,E-mail address: jes@aun.edu.eg 
Amir R. A. Ghani, M. A. Hassan, Axial Crush Behaviour of Square Column with External Tapered Plunger, pp. 1498 - 1517

Table 1.

Design dimensions

\begin{tabular}{|c|c|c|}
\hline Design & $\begin{array}{c}\text { Plain } \\
\text { column }\end{array}$ & $\begin{array}{c}\text { Column with } \\
\text { External plunger }\end{array}$ \\
\hline $\begin{array}{c}\text { Length, L } \\
(\mathrm{mm})\end{array}$ & 250 & 250 \\
\hline $\begin{array}{c}\text { Width, D } \\
(\mathrm{mm})\end{array}$ & 50 & 50 \\
\hline $\begin{array}{c}\text { Column wall } \\
\text { thickness, } \mathrm{t}_{1} \\
(\mathrm{~mm})\end{array}$ & 1.57 & 20 \\
\hline $\begin{array}{c}\text { Plunger height, } \\
\text { H (mm) }\end{array}$ & - & $20,30,40,50$ \\
\hline $\begin{array}{c}\text { Plunger angle, } \theta \\
\text { (degree) }\end{array}$ & - & \\
\hline
\end{tabular}

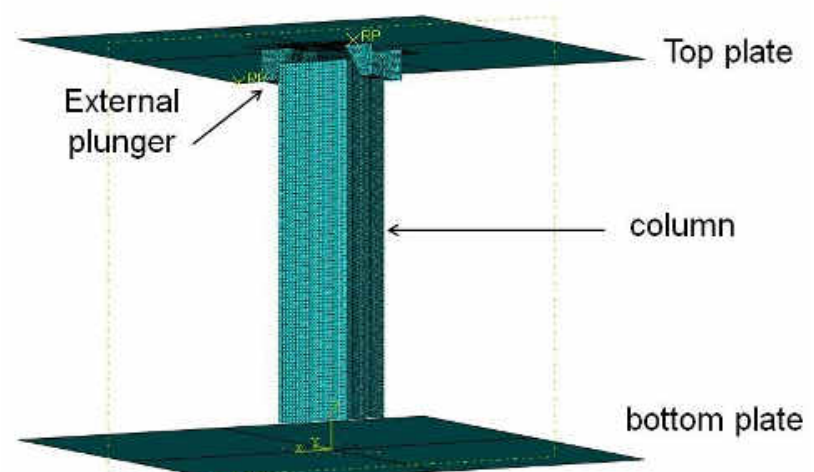

Fig. 2. Finite Element model of Square Column with External Plunger

Table 2.

General Properties of Aluminium 6063-T5

\begin{tabular}{|l|c|}
\hline Density & $2700 \mathrm{~kg} / \mathrm{m}^{3}$ \\
\hline Ultimate tensile strength (UTS) & $220 \mathrm{MPa}$ \\
\hline Yield strength & $180 \mathrm{MPa}$ \\
\hline Young's Modulus & $65 \mathrm{GPa}$ \\
\hline Poisson's Ratio & 0.3 \\
\hline
\end{tabular}

Journal of Engineering Sciences, Assiut University, Faculty of Engineering, Vol. 41, No. 4, July, 2013, E-mail address: jes@aun.edu.eg 


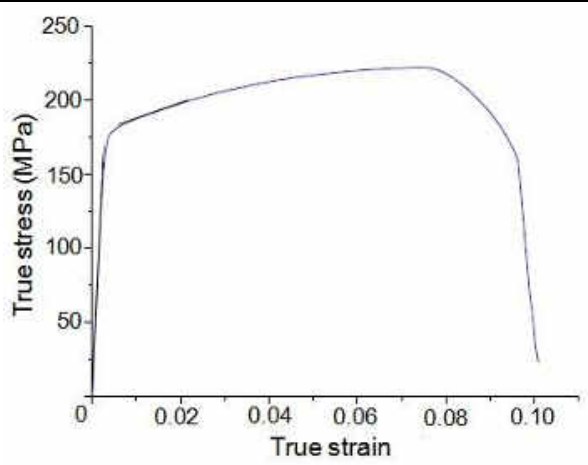

Fig. 3. Experimental true stress-strain curve for Aluminium 6063-T5

A dynamic explicit solver Abaqus/Explicit was used to run the analysis. The contact behavior between all the components during impact was set up under the interaction module. The contact property consisted of tangential behavior, which used a 'penalty' friction formulation with a coefficient of 0.25 . The normal behavior used the 'hard contact' formulation to allow separation of bodies after contact. A general dynamic (explicit) contact was utilized where all the contact surfaces including self contact were automatically identified by the system.

The two designs were subjected to both static and dynamic axial loadings. In static loading, the top plate was moved down by $70 \%$ of the column length to ensure maximum effective crushing. A suitable time scaling was used to ensure that the effect of inertia is negligible for quasi-static loading. In dynamic loading, a drop mass of $50 \mathrm{~kg}$ and impact speed of $10 \mathrm{~m} / \mathrm{s}$ were specified. Time duration of $0.03 \mathrm{~s}$ was specified to ensure sufficient time for crushing the tube and for the drop hammer to come to rest.

The boundary conditions for the top plate were $\mathrm{V} 1=\mathrm{V} 2=\mathrm{VR} 1=\mathrm{VR} 2=\mathrm{VR} 3=0$, which implies that the plate could only move in the vertical z-direction. The bottom plate was fully constrained. The bottom edges of the column were constrained in the z-direction only. Movement of the column in the $\mathrm{x}$ - and $\mathrm{y}$-direction was restrained by the friction between the column and the bottom plate.

The simulation results were validated by experiments before embarking in parametric study. This is to ensure accuracy and validity of the simulation results. For dynamic loading, a drop mass of $38 \mathrm{~kg}$ and impact speed of $4.4 \mathrm{~m} / \mathrm{s}$ were used. The selected values were achievable by the existing experimental test rig.

\section{Experiments}

Quasi-static tests were performed on the Instron 3382 universal testing machine. The machine has a maximum crosshead speed of $200 \mathrm{~mm} / \mathrm{min}$ and maximum load of $100 \mathrm{kN}$. The machine is connected to a controller PC which has dedicated data acquisition and analysis software i.e. Bluehill. Standard length columns were made by extrusion method

Journal of Engineering Sciences, Assiut University, Faculty of Engineering, Vol. 41, No. 4, July, 2013,E-mail address: jes@aun.edu.eg 
Amir R. A. Ghani , M. A. Hassan, Axial Crush Behaviour of Square Column with External Tapered Plunger, pp. $1498-1517$

and heat treated. The columns were then cut into required length. The external plunger was made from mild steel and machined using CNC milling machine. Sample was positioned between the compression platen as shown in Figure 4 and the load was applied at 5 $\mathrm{mm} / \mathrm{min}$.

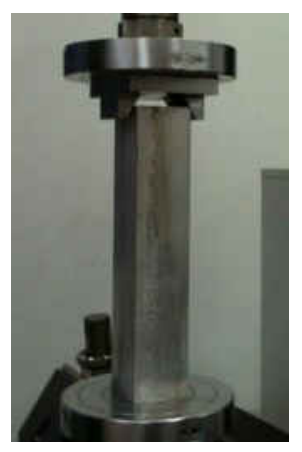

Fig. 4. Specimen positioning and loading arrangement for static loading

Dynamic tests were performed on the Instron Dynatup 8250 test rig as shown in Figure 5. The machine can be fitted with a drop mass ranging from $3 \mathrm{~kg}$ to $40 \mathrm{~kg}$. With a drop height of $1 \mathrm{~m}$ and spring assisted, a maximum speed of $4.4 \mathrm{~m} / \mathrm{s}$ and impact energy of $500 \mathrm{~J}$ can be achieved. Position transducer is of optical encoder type and force transducer is of strain gauge/ piezoelectric type. The test rig is connected to a controller PC which includes dedicated data acquisition and analysis software.

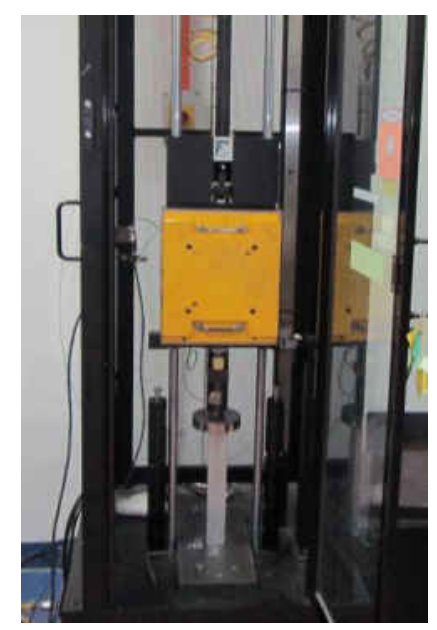

Fig. 5. Specimen positioning and loading arrangement for dynamic loading

Journal of Engineering Sciences, Assiut University, Faculty of Engineering, Vol. 41, No. 4, July, 2013,E-mail address: jes@aun.edu.eg 


\section{Analytical model}

For the plain column, progressive collapse of the walls occurs when stress has reached its yield stress. The force required to cause yield stress is equivalent to the initial peak force. The high initial peak force is needed to overcome the initial bending resistance of column sides. Once initial yield stress is reached and the column sides start folding, there is a considerable reduction of force as there is less resistance to bending. The resulting stress field within the column ensures that lower force is needed to cause subsequent folding of the column sides.

Initial peak force for the plain column is given by,

$$
F_{I P F}=4 \sigma_{o} D t_{1}
$$

where,

$\sigma o=$ yield stress $(\mathrm{Pa})$

$\mathrm{D}=$ width of column $(\mathrm{m})$

$\mathrm{t} 1=$ thickness of column wall $(\mathrm{m})$

Analytical model of the column with external plunger is modified based on the model by Wierzbicki and Abramovicz [10] for plain column. With the addition of the external plunger, just before the impactor hits the top of the column, the column will have initial deformation as shown in Figure 6.

In general, the total energy absorbed during impact is the sum up of the energies dissipated in the plastic deformation, plastic stationary hinge and plastic travelling hinge as bending of column sides moves with the plunger in addition to friction energy between the plunger and column sides.

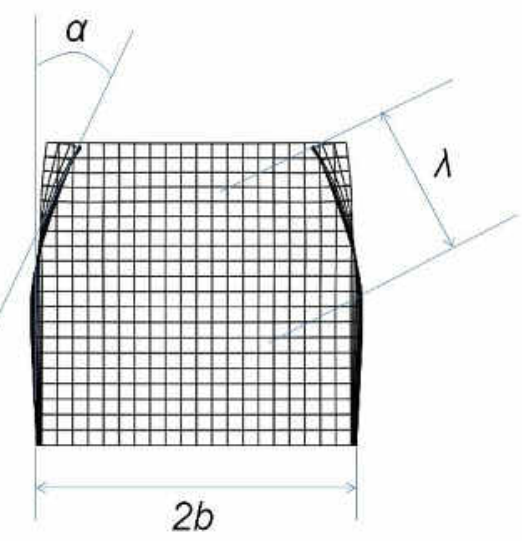

Fig. 6. Deformation of column with external plunger before impactor hits the column

Journal of Engineering Sciences, Assiut University, Faculty of Engineering, Vol. 41, No. 4, July, 2013,E-mail address: jes@aun.edu.eg 
Amir R. A. Ghani, M. A. Hassan, Axial Crush Behaviour of Square Column with External Tapered Plunger, pp. 1498 - 1517

In the present analytical model, the stationary hinge will be replaced by a travelling hinge as bending of column sides moves with the plunger. Friction between the plunger and column sides is due to the sliding contact between them.

Rate of energy dissipation for each item is now given by,

$W_{1}=2 M_{o} \lambda C_{1} \sin 2 \alpha \cdot \frac{r}{t_{1}} . \alpha$

$W_{2}=2 M_{o} L \frac{v}{r_{h}} \delta=\frac{6 M_{o} b \lambda \sin \alpha \cdot \alpha}{r_{2}}$

$W_{3}=2 M_{o} \frac{\lambda^{2}}{r} C_{3} \frac{0.9 \cos \alpha}{\left(1+\sin ^{2} \alpha\right)^{0.5}} . \alpha$

$W_{\text {fric }}=\mu P \sin \alpha \delta \cos \alpha=\mu P \sin ^{2} \alpha \cdot 2 \lambda \cos \alpha \cdot \alpha$

Total rate of energy dissipation,

$P 2 \lambda(\sin \alpha) \alpha=W_{1}+W_{2}+W_{3}+W_{\text {fric }}$

The instantaneous crushing force, $\mathrm{P}$ is given by,

$P=\frac{\left(\frac{2 C_{1} \sin 2 \alpha \cdot r}{t_{1}}+\frac{6 b \sin \alpha}{r_{h}}+\frac{2 \lambda C_{3} 0.9 \cos \alpha}{r\left(1+\sin ^{2} \alpha\right)^{0.5}}\right) M_{o} \lambda}{2 \lambda \sin \alpha(1-\mu \sin \alpha \cos \alpha)}$

where,

$\mathrm{C} 1$, and $\mathrm{C} 3$ are constant coefficients [8]

$\mathrm{C} 1=4.64$

$\mathrm{C} 3=2.22$

$\mathrm{t} 1=$ thickness of column $(\mathrm{m})$

$\mathrm{b} \quad=$ half width of column (m)

$\lambda=$ half length of fold $(\mathrm{m})$

$\mathrm{r} \quad=$ radius of toroid at corner $(\mathrm{m})$

$\mathrm{rh} \quad=$ hinge radius $(\mathrm{m})$

$\sigma o=$ yield stress $(\mathrm{N} / \mathrm{m} 2)$

$\alpha$ or $\theta=$ inclined angle (o)

$\mu \quad=$ coefficient of friction

$\mathrm{H} \quad=$ plunger height $(\mathrm{m})$

Mo is the plastic bending moment per unit length and given by,

$M_{o}=\frac{\sigma_{o} t_{1}^{2}}{4}$

Journal of Engineering Sciences, Assiut University, Faculty of Engineering, Vol. 41, No. 4, July, 2013,E-mail address: jes@aun.edu.eg 
And,

$$
\begin{gathered}
\lambda=\frac{H}{2 \cos \alpha} \\
r=0.687 \sqrt[3]{t_{1}^{2} b}
\end{gathered}
$$

Since equation 9 is for quarter section of column, it should be multiplied by 4 to give the instantaneous crush force for the whole column section.

\section{Results and discussion}

\section{1. FE-Model Validation}

Figure 7 shows the comparison between simulation and experimental results for plain column subjected to static loading. Both results showed high initial peak forces followed by lower fluctuating mean forces. The increase of forces toward the end of the crush travel indicated that the columns were bottomed out. Figure 8 shows the final deformed shapes. Column failed in progressive buckling mode.

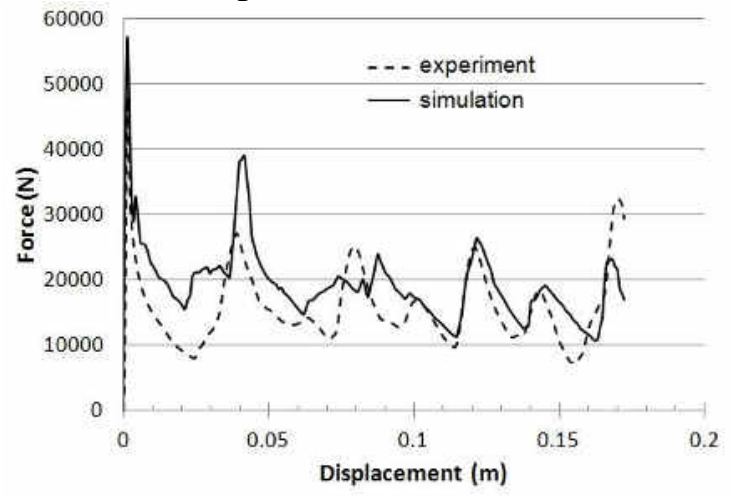

Fig. 7. Simulation and experimental static crushing responses for plain column

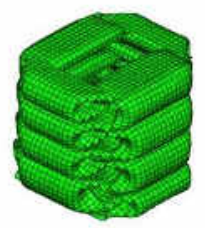

simulation

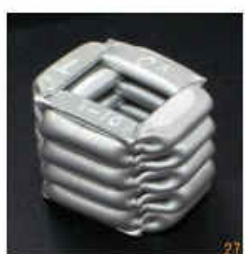

experiment

Fig. 8. Simulation and experimental deformed shapes for plain column subjected to static loading

Journal of Engineering Sciences, Assiut University, Faculty of Engineering, Vol. 41, No. 4, July, 2013,E-mail address: jes@aun.edu.eg 
Amir R. A. Ghani, M. A. Hassan, Axial Crush Behaviour of Square Column with External Tapered Plunger, pp. $1498-1517$

Figure 9 shows the comparison between simulation and experimental results for column with external plunger subjected to static loading. Both results showed substantial decrease in initial peak force as compared to plain column, which verifying the effectiveness of the trigger mechanism. Figure 10 shows the final numerical and experimental deformed shapes. Both results showed similar folding pattern where the top edges of columns followed the shape of the external plunger. Static simulation results compared favorably with the experimental results, thus validating the modeling technique and accuracy of the Abaqus explicit code. The simulation was able to predict with reasonable accuracy the initial peak force (IPF), the mean force and the number of folds during progressive failure of column.

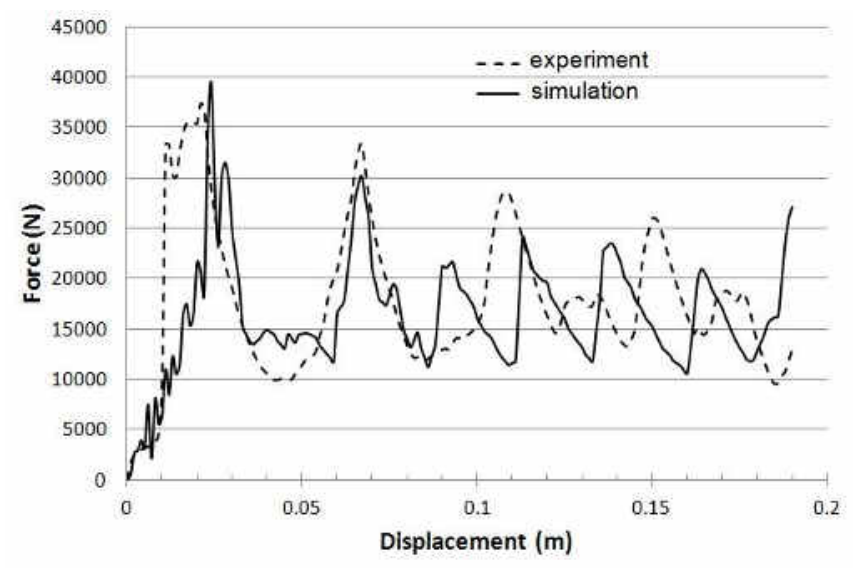

Fig. 9. Simulation and experimental static crushing responses for column with external plunger

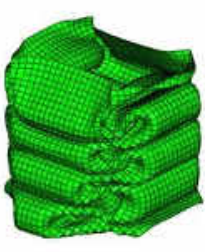

simulation

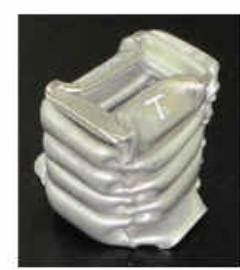

experiment

Fig. 10. Numerical and experimental deformed shapes for column with external plunger subjected to static loading

Journal of Engineering Sciences, Assiut University, Faculty of Engineering, Vol. 41, No. 4, July, 2013,E-mail address: jes@aun.edu.eg 
1509

Amir R. A. Ghani , M. A. Hassan, Axial Crush Behaviour of Square Column with External Tapered Plunger, pp. 1498 - 1517

Figures 11 and 12 show the comparison between simulation and experimental results for plain column and column with external plunger subjected to dynamic loading. In general, both designs showed good agreements between simulations and experiments. Dynamic response of plain column has similar trends to the static response. However, experimental results showing slightly lower initial peak force and mean force as compared to the simulation results. For the dynamic response of column with plunger there was a distinct and abrupt fluctuation in force before the initial peak force was reached. This could be due the sliding of the plunger against the column faces. Experimental results showed slightly higher initial peak force and sharper peaks as compared to the simulation results.

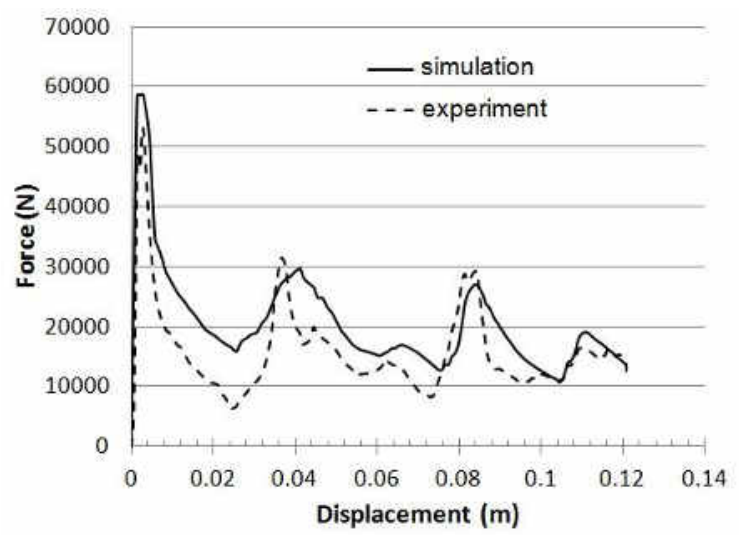

Fig. 11. Simulation and experimental dynamic crushing responses for plain column

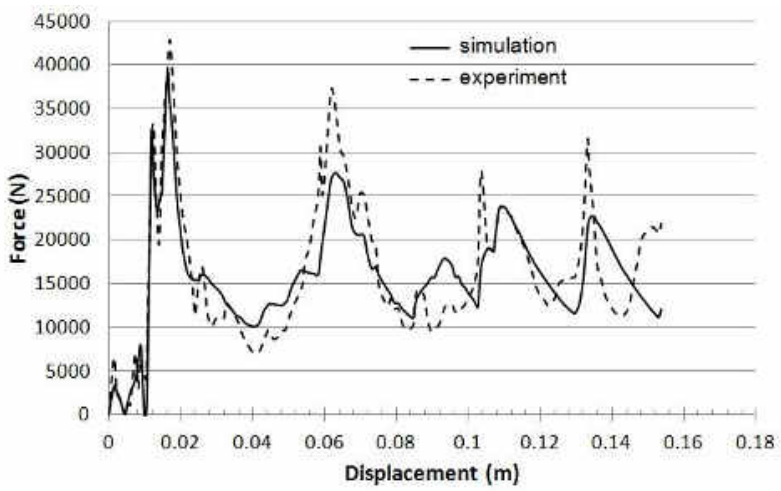

Fig. 12. Simulation and experimental dynamic crushing responses for column with external plunger

Journal of Engineering Sciences, Assiut University, Faculty of Engineering, Vol. 41, No. 4, July, 2013,E-mail address: jes@aun.edu.eg 
Amir R. A. Ghani, M. A. Hassan, Axial Crush Behaviour of Square Column with External Tapered Plunger, pp. $1498-1517$

\section{2. Static loading}

Figure 13 shows the static responses for plain column and column with external plunger with different taper angles. Plain column showed a sudden high initial peak force followed by lower fluctuating mean forces. Column with external plunger showed much lower initial peak forces which occurred at longer crushing distance as compared to plain column. Column with external plunger with taper angles of 40 and 50 had initial peak forces which were equal and similar to their fluctuating mean forces. Overall, all designs showed similar fluctuating mean forces which implying that the addition of plunger has only reduced the initial peak force. Column with external plunger showed more gradual increase of force until the initial peak force occurred. This was due to the initial sliding of the plunger against the column faces plus folding and unfolding of column faces before the impactor hit the top of column.

Figure 14 shows the failure modes for plain column and columns with plungers of different taper angles under static loading. All designs exhibited progressive buckling failure mode. The plunger only affected the top portion of the column where the top portion followed the shape of the plunger. Subsequent folding of the column was not affected, hence the similar subsequent fluctuating mean forces were observed. The function of the plunger is to create initial deformation on the column just before the impactor hit the column. The initial deformation reduced the bending resistance of the side walls. This facilitated the progressive buckling of the column and reduced the initial peak force.

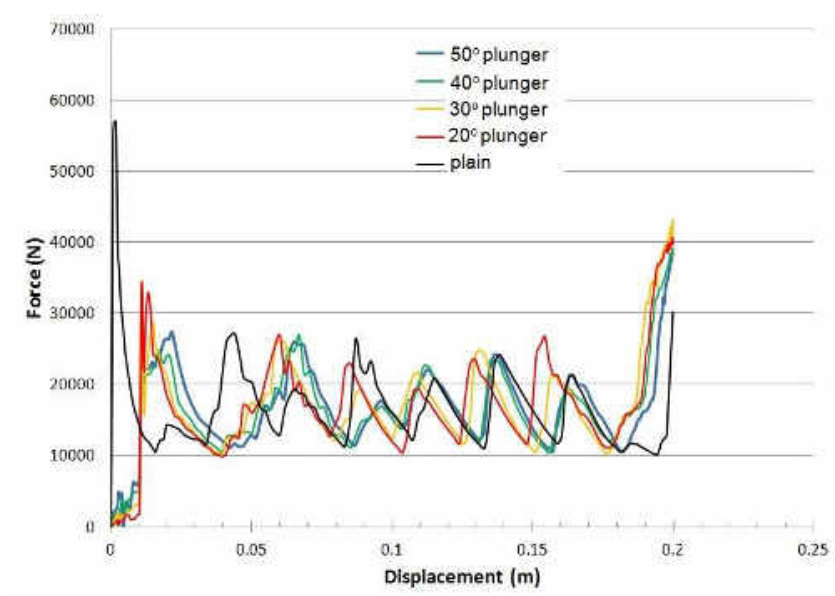

Fig. 13. Static crushing response for plain column and column with external plunger with different taper angles

Journal of Engineering Sciences, Assiut University, Faculty of Engineering, Vol. 41, No. 4, July, 2013,E-mail address: jes@aun.edu.eg 
Amir R. A. Ghani , M. A. Hassan, Axial Crush Behaviour of Square Column with External Tapered Plunger, pp. 1498 - 1517
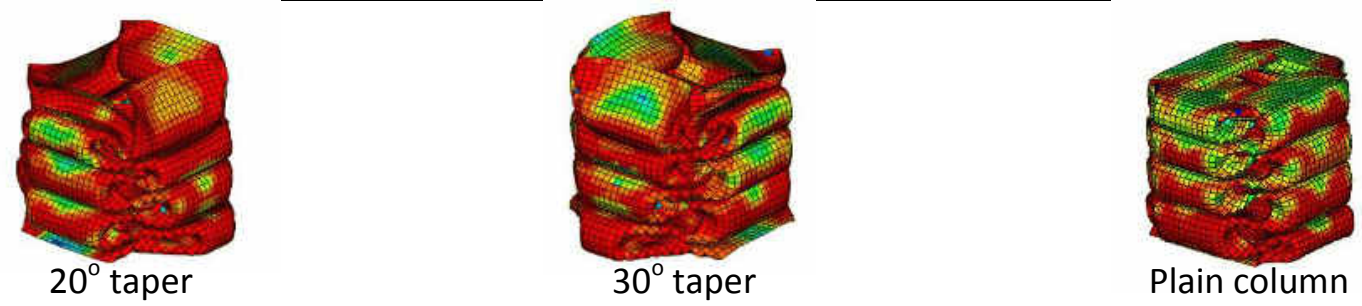

Plain column

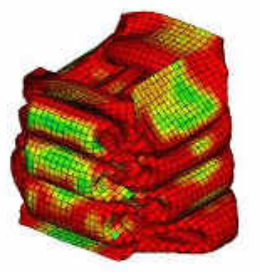

$40^{\circ}$ taper

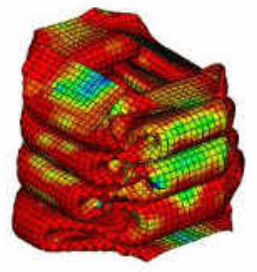

$50^{\circ}$ taper

Fig. 14. Failure modes for plain column and columns with external plungers of different taper angles under static loading

Figure 15 shows the IPF for the plain column and columns with external plunger with different taper angles under static loading. The plain column has the highest IPF of 57265 N. Overall, increasing the plunger taper angle from $20 \mathrm{o}$ to $50 \mathrm{o}$ gradually reduce the IPF with the 50o plunger giving the lowest IPF of $27307 \mathrm{~N}$. Column with 30o plunger showed a slight increase in IPF as compared to the column with 20o plunger.

Figure 16 shows the CFE for the plain column and columns with external plunger with different taper angles under static loading. As shown, increasing the taper angle increases the CFE. Plunger angle of 50o has shown the highest CFE value of 59.7\%. While the plain column showed the lowest CFE of 29.9\%. Column with 30o plunger angle showed a slight decrease in CFE as compared to column with 20o plunger. From the static force displacement responses for columns with plungers, mean forces were all similar. Therefore, the value of CFE was influenced more by the initial peak force, IPF.

Figure 17 shows the SEA for the plain column and columns with external plunger with different taper angles under static loading. The plain column had the highest SEA of 17104 $\mathrm{J} / \mathrm{kg}$ as it had more crushing zone at its top portion. Increasing the plunger taper angle from 20o to 50o slightly decreased the SEA of columns. Column with 50o plunger had the lowest SEA of $15377 \mathrm{~J} / \mathrm{kg}$. Increasing the taper angle has reduced the bending stiffness of the column sides hence less force and energy were required to crush the column.

Journal of Engineering Sciences, Assiut University, Faculty of Engineering, Vol. 41, No. 4, July, 2013,E-mail address: jes@aun.edu.eg 
Amir R. A. Ghani, M. A. Hassan, Axial Crush Behaviour of Square Column with External Tapered Plunger, pp. 1498 - 1517

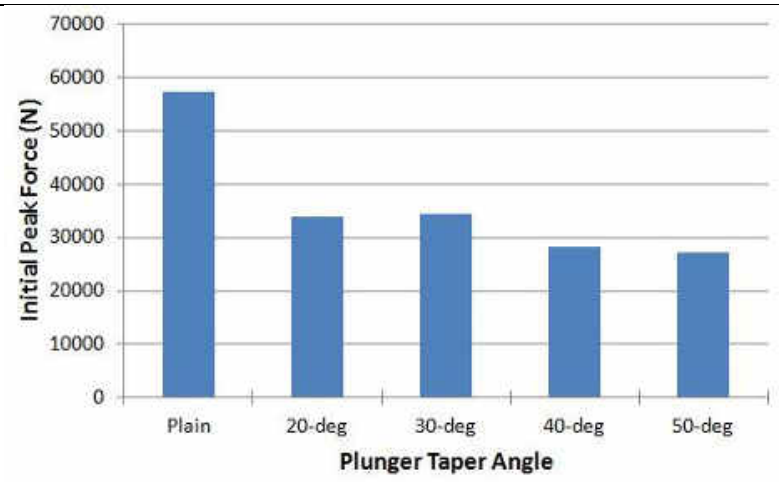

Fig. 15. Initial peak forces for static loading

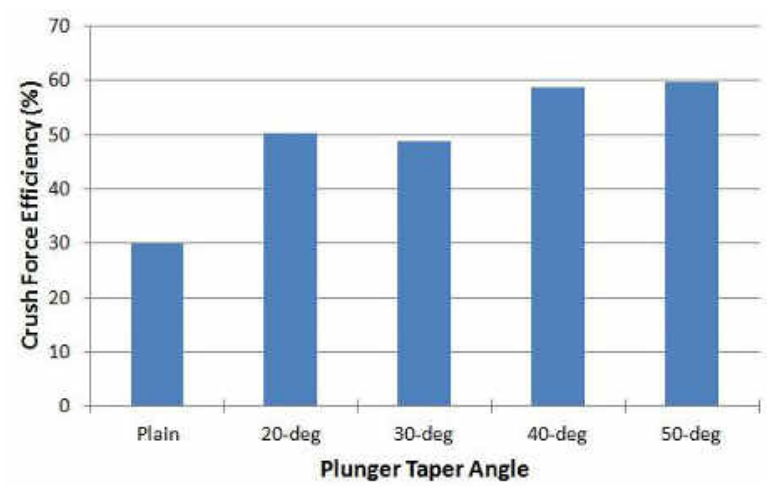

Fig. 16. Crush force efficiency for static loading

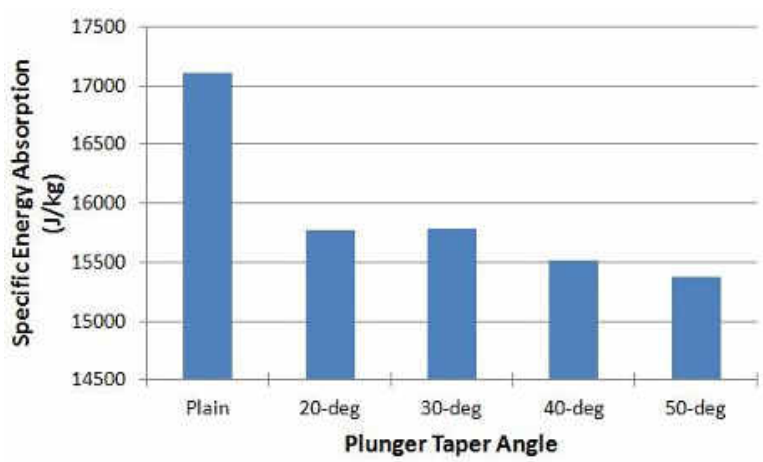

Fig. 17. Specific energy absorption for static loading

Table 3 shows the change of crush performance indices of columns with external plungers as compared to plain column subjected to static loading. Column with $50 \mathrm{o}$ degree plunger had the lowest IPF which is a reduction of 52.3\% as compared to the plain column. This column also has the highest CFE, which gives an increase of $99.7 \%$ as compared to

Journal of Engineering Sciences, Assiut University, Faculty of Engineering, Vol. 41, No. 4, July, 2013,E-mail address: jes@aun.edu.eg 
Amir R. A. Ghani , M. A. Hassan, Axial Crush Behaviour of Square Column with External Tapered Plunger, pp. $1498-1517$

the plain column. All columns with plungers showed reduction in SEA as compared to the plain column. Column with 50o plunger fared the worst with a reduction of $10.1 \%$.

Table 3.

Change of crush performance indices of columns with external tapered plunger compared to plain column under static loading

\begin{tabular}{|l|l|c|c|c|c|}
\hline & Plain & \multicolumn{4}{|c|}{ \% change } \\
\cline { 3 - 6 } & column & $20^{\circ}$ & $30^{\circ}$ & $40^{\circ}$ & $50^{\circ}$ \\
\hline IPF (N) & 57265 & -40.8 & -39.8 & -50.6 & -52.3 \\
\hline CFE (\%) & 29.9 & +67.9 & +63.5 & +96.7 & +99.7 \\
\hline SEA (J/kg) & 17104 & -7.8 & -7.7 & -9.3 & -10.1 \\
\hline
\end{tabular}

(Note: '+' denotes increase, '-' denotes decrease)

Figure 18 shows the comparison of IPF between FE-simulation and analytical model (theory) for columns with external plungers. Both methods showed decreasing value of IPF with increasing plunger taper angle. For taper angle of 20o, analytical model over-predicted the IPF as compared to the simulation result. For taper angle of $30 \mathrm{o}$ and greater, the theoretical model under predicted the IPF as compared to simulation. One possible reason for this difference is that at higher taper angles, there could be additional failure mechanism that contributed towards crushing of the column is not included in the analytical model. Another could be due to model assumptions and ideal plastic deformation condition.

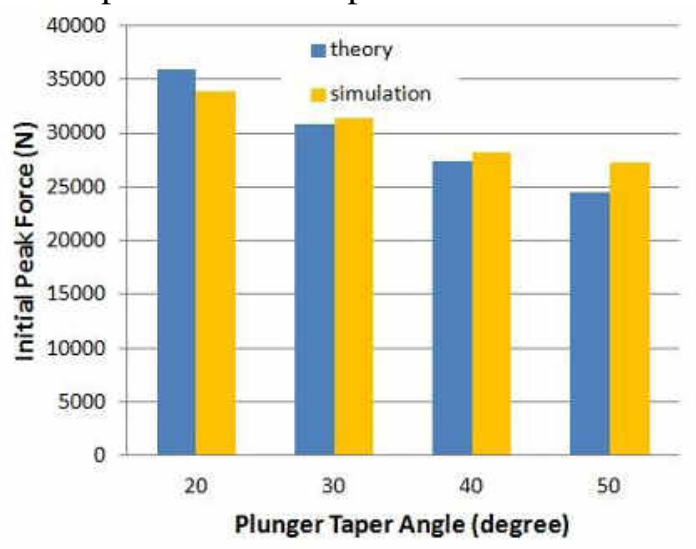

Fig. 18. Comparison of IPF between FE-simulation and analytical model (theory) for columns with external plungers

\section{3. Dynamic loading}

Figure 19 shows the dynamic responses for plain column and column with external plunger with different taper angles. All designs showed high initial peak forces with lower subsequent fluctuating mean forces. Similar to the static crushing response, the plain column has a sudden high initial peak force. Columns with plungers showed initial fluctuations before reaching their initial peak forces. Dynamic simulations showed more

Journal of Engineering Sciences, Assiut University, Faculty of Engineering, Vol. 41, No. 4, July, 2013,E-mail address: jes@aun.edu.eg 
Amir R. A. Ghani , M. A. Hassan, Axial Crush Behaviour of Square Column with External Tapered Plunger, pp. 1498 - 1517

jagged responses especially in the first folding of the columns. The responses smoothened out at higher crushing distance. Columns with plunger angles greater than $20 \mathrm{o}$ showed substantial reduction of initial peak force as compared to the plain column.

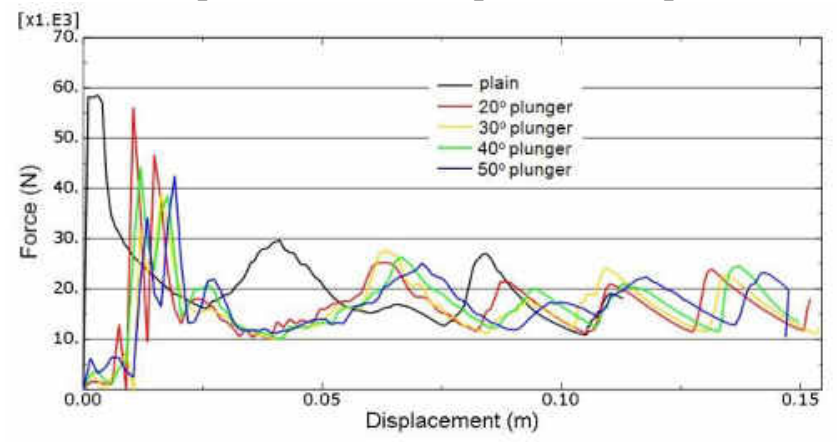

Fig. 19. Dynamic crushing response for plain column and column with external plunger with different taper angles

Figure 20 shows the failure modes for plain column and columns with plungers of different taper angles under dynamic loading. All designs exhibited progressive crushing failure mode. Inward folding of the top of the column by the plunger seemed to induce uniform folding of the column. The plunger influenced the folding pattern and the starting location of the fold. At higher taper angles, folding of the column top edges was more prominent. For the plain column, folding initiated in the middle of the column and progressed to the bottom of the column. Folding pattern was less uniform as compared to the columns with plungers.

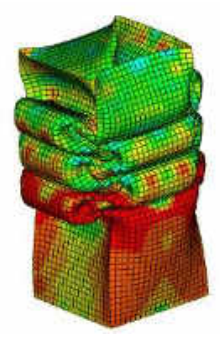

$20^{\circ}$ taper

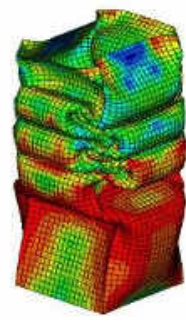

$40^{\circ}$ taper

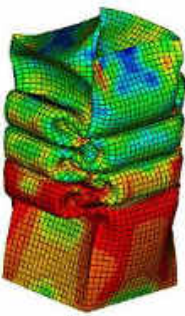

$30^{\circ}$ taper

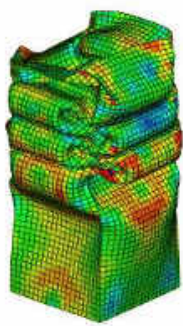

$50^{\circ}$ taper

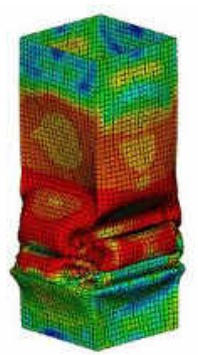

Plain column

Fig. 20. Failure modes for column with external plunger under dynamic loading

Journal of Engineering Sciences, Assiut University, Faculty of Engineering, Vol. 41, No. 4, July, 2013,E-mail address: jes@aun.edu.eg 
1515

Amir R. A. Ghani , M. A. Hassan, Axial Crush Behaviour of Square Column with External Tapered Plunger, pp. 1498 - 1517

Figure 21 shows the IPF for all designs under dynamic loading. The plain column has the highest IPF of $58106 \mathrm{~N}$. All columns with plunger angle greater than 20o showed substantial reduction in IPF as compared to the plain column. Column with 20o plunger angle showed a slight reduction in IPF whereas column with 30o plunger has shown the lowest IPF of about $38782 \mathrm{~N}$. Generally, increasing the plunger angle has reduced the IPF.

Figure 22 shows the CFE for all designs under dynamic loading. Column with a 50o plunger has the highest CFE of $41.7 \%$. Columns with plunger angle greater than 20 o have higher CFE as compared to the plain column. Column with 200 plunger angle has the lowest CFE of $29.3 \%$. Generally, increasing the plunger angle has increased the CFE.

Figure 23 shows the SEA for all designs. All designs show similar values of SEA. Plain column has the highest SEA of $11684 \mathrm{~J} / \mathrm{kg}$ while column with 50o plunger has the lowest SEA of $11552 \mathrm{~J} / \mathrm{kg}$. The plain column has more compact folds that resulted in higher SEA as compared to column with plungers. The plunger improved the IPF and CFE of the column while maintaining the SEA.

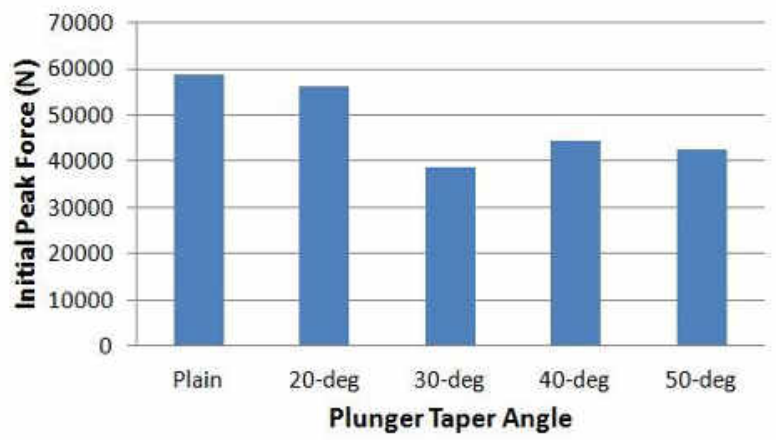

Fig. 21. Initial peak forces for dynamic loading

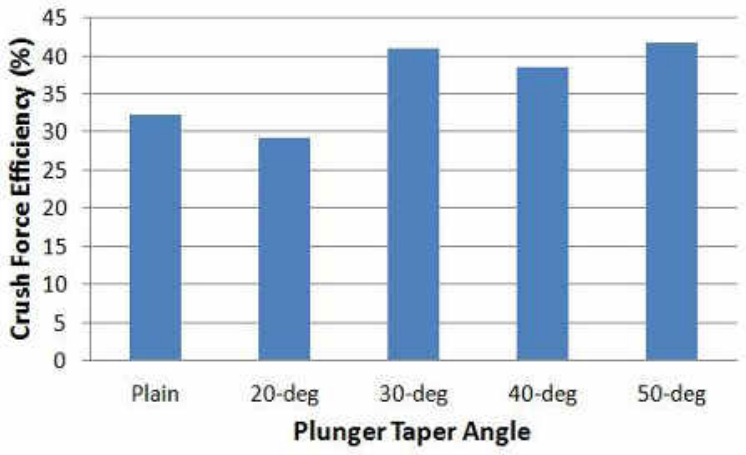

Fig. 22. Crush force efficiency for dynamic loading

Journal of Engineering Sciences, Assiut University, Faculty of Engineering, Vol. 41, No. 4, July, 2013, E-mail address: jes@aun.edu.eg 
Amir R. A. Ghani, M. A. Hassan, Axial Crush Behaviour of Square Column with External Tapered Plunger, pp. 1498 - 1517

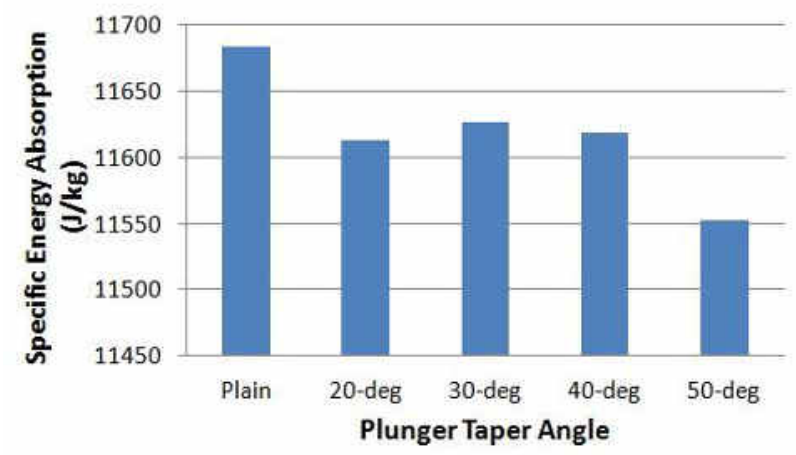

Fig. 23. Specific energy absorption for dynamic loading

Table 4 shows change of the crush performance indices of columns with external plungers as compared to plain column subjected to dynamic loading. Column with 30o degree plunger had the lowest IPF with $33.8 \%$ reduction as compared to the plain column. Column with 50o plunger had the highest CFE, which gives an increase of $29.5 \%$ as compared to the plain column. All columns with plungers showed negligible reduction in SEA as compared to the plain column. Column with 50o plunger showed a reduction of $1.1 \%$.

Table 4.

Change of crush performance indices of columns with external tapered plunger compared to plain column under dynamic loading

\begin{tabular}{|l|l|c|c|c|c|}
\hline & Plain & \multicolumn{5}{|c|}{$\%$ change } \\
\cline { 3 - 6 } & column & $20^{\circ}$ & $30^{\circ}$ & $40^{\circ}$ & $50^{\circ}$ \\
\hline IPF (N) & 58610 & -4.3 & -33.8 & -24.4 & -27.4 \\
\hline CFE (\%) & 32.2 & -9 & +27 & +19.3 & +29.5 \\
\hline SEA (J/kg) & 11684 & -0.006 & -0.005 & -0.006 & -1.1 \\
\hline \multicolumn{2}{|c}{ (Note: ' $++^{\prime}$ denotes increase, '-' denotes decrease) }
\end{tabular}

\section{Conclusions}

Crush performance of standard square columns was improved by the use of external tapered plunger as a trigger mechanism. The effects of plunger angle on initial peak force (IPF), crush force efficiency (CFE), specific energy absorption (SEA) were studied by FE-model under axial static and dynamic loading whereas the simulations results were validated by experiments.

In static loading, columns with plungers showed substantial improvement in IPF and CFE indices. It was also found that, increasing the plunger angle reduced the IPF and increased the CFE. Column with 50o plunger gave the lowest IPF and highest CFE. The IPF was reduced by $52.8 \%$ and CFE increased by $99.7 \%$ whereas SEA for all columns was comparable.

For dynamic loading, columns with plungers showed noticeable improvement in IPF. Column with 30o plunger angle gave the lowest IPF with $33.8 \%$ reduction as compared to the plain column. In term of CFE, column with plunger angle of $30 \mathrm{o}$ and greater showed $29.5 \%$

Journal of Engineering Sciences, Assiut University, Faculty of Engineering, Vol. 41, No. 4, July, 2013,E-mail address: jes@aun.edu.eg 
improvement. Column with 50o plunger gave the highest CFE. In term of SEA, all columns showed similar values whereas the plain column gave the highest SEA index. This showed that the plungers have improved the IPF and CFE of the column while maintaining the SEA.

The authors believe that the present proposed trigger mechanism will find vast applications in dynamic energy absorber system for front car collision.

\section{References}

[1] Johnson, W. (1996). Introduction to Crashworthiness. International Journal of Crashworthiness. 1(1): pp 5-10

[2] Jones, N. (1997). Structural Impact. Cambridge University Press.

[3] $\mathrm{Yu}, \mathrm{T} . \mathrm{X}$. and Lu, G. (2003). Energy absorption of structures and materials, Woodhead Publishing, Cambridge, United Kingdom.

[4] Xiong Zhangm and Gengdong Cheng. (2007). A comparative study of energy absorption characteristics of foam filled and multi square columns. Int. Journal of Impact Engineering. 34: pp. 1739-1752.

[5] G.H. Daneshi and S.J. Hosseinipou. (2003). Grooves effect on crashworthiness characteristics of thin walled tubes under axial compression. Materials and Design. 23: pp.611-617.

[6] Xiong Zhang, Gengdong Cheng and Hui Zhang. (2009). Numerical investigation on a new type of energy absorbing structure based on free inversion of tubes. Int. Journal of Mechanical Sciences. 51: pp.64-76.

[7] Zhang, X.W., Su, H. and Yu, T.X. (2009). Energy absorption of an axially crushed square tube with a buckling initiator. Int. Journal of Impact Engineering. 36: 402-417.

[8] Zhang, X.W, Tian, Q.D and Yu, T.X. (2009). Axial crushing of circular tubes with buckling initiators. Thin Walled Structures.47: 788-797.

[9] Yamashita, M., Kenmotsu, H. and Hattori, T. (2012). Dynamic axial compression of aluminium hollow tubes with hat cross-section and buckling initiator using inertia force during impact. Thin Walled Structures. 50: 37-44

[10] Wierzbicki, T. and Abramowicz, W. (1983). On the crushing mechanics of thin walled structures. Journal of Applied Mechanics. 50(4a): pp727-734.

\section{سلوك التحطم بالصدم العمودى لماسورة مربعة مزودة بمضرب خارجى مسلوب الملخص العربى

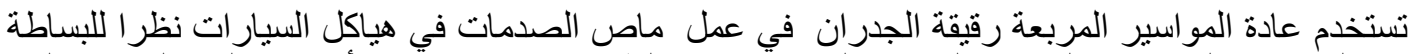

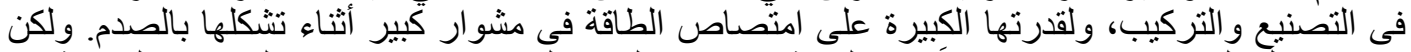

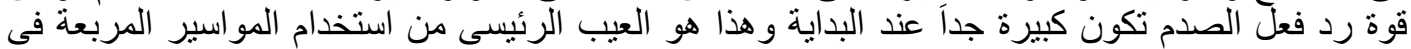

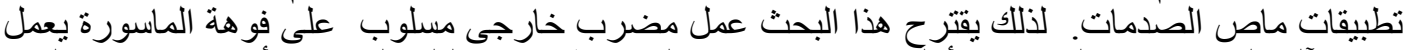

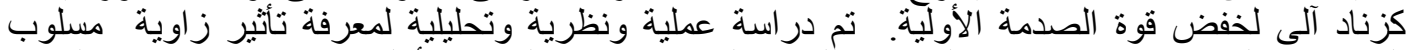

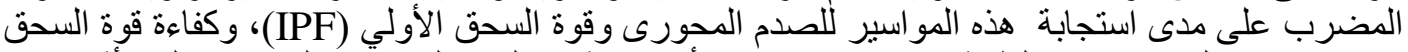

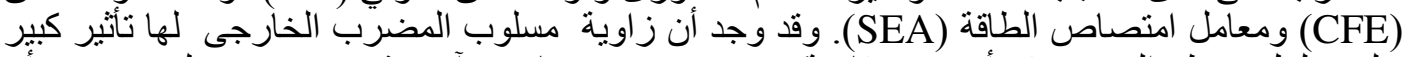

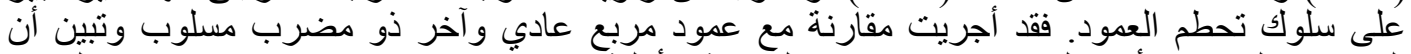 المضرب الخارجى أدى إلى خفى فضى فى قوة الصى الصىدمة الأولية بمقدار

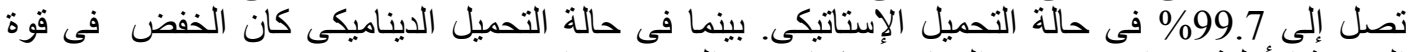

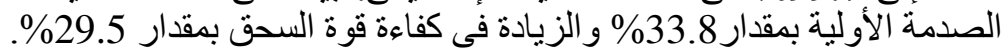

Journal of Engineering Sciences, Assiut University, Faculty of Engineering, Vol. 41, No. 4, July, 2013,E-mail address: jes@aun.edu.eg 